\title{
Outcomes of Maximum Levator Resection in Severe Upper Eyelid Ptosis at a Tertiary Oculoplastic Service
}

\author{
Mohammad Idris ${ }^{1}$, Hassan Yaqoob ${ }^{2}$, Hadia Sabir ${ }^{3}$, Hera Fahim ${ }^{4}$, Muhammad Jamshed ${ }^{5}$ \\ 1,3,4,5 Lady Reading Hospital, Medical Teaching Hospital, ${ }^{2}$ North West Teaching Hospital, Peshawar
}

\begin{abstract}
Purpose: To investigate the surgical outcomes of maximum Levator resection in cases of severe upper eyelid ptosis at a tertiary oculoplastic service.
\end{abstract}

Study Design: Interventional case series.

Place and Duration of Study: Department of Ophthalmology, Lady Reading Hospital, Medical Teaching Hospital, Peshawar January 2013 to December 2017.

Methods: One hundred and twenty three eyes of 107 patients, who underwent maximum levator resection for severe congenital ptosis were included. Patients with missing or incomplete notes, patients with previous ptosis surgery and ptosis other than congenital were excluded. Maximum levator resection of the muscle above the Whitnall ligament was performed under local/general anesthesia. All patients had a minimum of 6 months and maximum of 5 years followup. The postoperative complications were recorded and followed. Post operative followup was done at day one, week one and at four weekly intervals till the end of the study.

Results: Out of 123 eyes, satisfactory results (excellent or good) were obtained in $111(90.1 \%)$ eyes. Majority of the patients $(56.09 \%)$ were females. Mean Preoperative Levator function was $2.3 \pm 1.1 \mathrm{~mm}$. Mean Preoperative MRD1 was $-0.1 \pm 1.5 \mathrm{~mm}$ and mean postoperative MRD1 was $3.9 \pm 01.0 \mathrm{~mm}$. The commonest complication was over correction which occurred in $5(4.06 \%)$ cases, under correction in $4(3.25 \%)$, crease abnormality in $2(1.62 \%)$ cases and entropion was seen in only one $(0.81 \%)$ case. Success rate was $90.1 \%$ at 6 months to 5 -years followup.

Key Words: Blepharoptosis; Levator resection; Levator function.

How to Cite this Article: Idris M, Yaqoob H, Sabir H, Fahim H, Jamshed M. Outcomes of Maximum Levator Resection in Severe Upper Eyelid Ptosis at a Tertiary Oculoplastic Service. Pak J Ophthalmol. 2022,38 (1): 4347.

Doi: $10.36351 /$ pjo.v38i1.1284

Correspondence: Mohammad Idris

Department of Ophthalmology

Lady Reading Hospital

Medical Teaching Hospital, Peshawar

Email: idrisdaud80@gmail.com

Received: June 1, 2021

Accepted: November 12, 2021

\section{INTRODUCTION}

Ptosis is a common and challenging oculoplastic procedure because of cosmetic and physiological implications, which depend on surgeon's own experience when deciding about choice of procedure. Greek word "ptosis" means falling and refers to drooping of eyelid when eye is in primary position. ${ }^{1}$ One of the commonest causes is simple congenital ptosis but sometimes it is associated with a lifethreatening condition. ${ }^{2}$ Most of the cases referred to 
our oculoplastic clinic are benign but systemic examination is important to exclude any systemic disease; for example myasthenia gravis and Horner syndrome. ${ }^{3}$

Ptosis is not only a major cosmetic concern but it can be an important cause of amblyopia in young children as well. ${ }^{4}$ Decision in such cases is based on severity of ptosis. Severe ptosis need early correction to prevent sight-threatening amblyopia. Severe congenital ptosis with poor levator function of $\leq 4 \mathrm{~mm}$ is not easy for the oculoplastic surgeon to deal with. ${ }^{5}$ The type of Surgery for the correction of congenital ptosis is based on surgeon's choice which may be frontalis suspension (FS) or MLR, Different studies are available which support both types. ${ }^{6}$ In both choices, the surgery is a challenge because of cosmetic and physiological implications. ${ }^{7}$

FS with different synthetic material is used to lift the droppy eyelid. This procedure is simple but there are certain issues which include bilateral surgery for symmetrical results, lack of crease formation, use of synthetic material in very young children and significant lagophthalmos leading to exposure. ${ }^{8}$ MLR is useful alternative in selected patients with severe ptosis which refers to resection of the muscle above the Whitnall ligament. ${ }^{9}$

In our present analysis, maximum levator resection (MLR) was done by a single surgeon. Rationale was to investigate the results of MLR in our set up. Such type of surgical audit is a useful tool to assess shortcomings and are important source to guide and improve results. ${ }^{10}$ It is beneficial both for the surgeon as well as the patients. We compared our results with different studies.

\section{METHODS}

One hundred and twenty three eyelids of 107 patients, who underwent maximum levator resection for severe congenital ptosis at oculoplastic service were included in this study. Twenty-one patients were lost to followup and excluded. Informed consent was taken. Newly diagnosed patients were included. Complete history and ocular examination was performed. A single consultant performed all the surgeries. Maximum levator resection of the muscle above the Whitnall ligament was performed under local/general anesthesia. The end-point of the surgery was to have the eyelid margin rest 1 to $2 \mathrm{~mm}$ below the super limbus with the patient under general anesthesia. All the patients had a minimum of 6 months and maximum of 5 years followup. Their success rate, postoperative complications and final outcome were assessed. Satisfactory surgical outcome was defined as postoperative MRD1 of $3 \mathrm{~mm}$ in each eye and difference in MRD1 of $1 \mathrm{~mm}$ between the two eyes at 6 months after surgery. The postoperative complications were recorded and followed. Success of surgery was defined on the basis of absent complications like lid abnormality, over or under correction and lid elevation with $1 \mathrm{~mm}$ lid covering the limbus at least at 6 months. Sutures were removed after two weeks. Complicated cases were assessed as to whether further surgery is required or not. Post operatively followup was done at day one, week one and at four weekly intervals till the end of the study.

\section{RESULTS}

Out of 123 eyes, satisfactory results (excellent or good result) were obtained in $111(90.1 \%)$. Sixteen cases were bilateral and 91 were unilateral out of 123 (107 patients) eyelids. Majority of patients $56.09 \%(\mathrm{n}=69)$ were females and males were $43.90 \%(\mathrm{n}=54)$. Patients were divided into three age groups. Maximum patients were in the age group of $7-27$ years $(55.28 \%, \mathrm{n}=68)$, patients of age $28-48$ years were $34.95 \%(n=43)$, while age groups $>48$ years were $9.75 \%(\mathrm{n}=12)$ patients. Preoperative and postoperative lid measurements for maximal levator resection was noted (Table 1). Different postoperative

Table 1: Eye Lid Measurements Before and After Maximal Levator Resection in Millimeter.

\begin{tabular}{clc}
\hline S. No. & Upper Eyelid Measurements & Mean \pm SD \\
\hline 1. & Preoperative LF & $2.3 \pm 1.1 \mathrm{~mm}$ \\
2. & Preoperative MRD1 & $-0.1 \pm 1.5 \mathrm{~mm}$ \\
3. & Postoperative MRD1 & $3.9 \pm 01.0 \mathrm{~mm}$ \\
\hline
\end{tabular}

$\mathrm{LF}=$ Levator Function, $\mathrm{mm}=$ Millimeter, $\mathrm{LF}=$ Levator Function, MRD1 = Upper Lid Marginal Reflex Distance, $\mathrm{SD}=$ Standard Deviation

complications are shown in table 2 and the commonest complication was over correction which occurred in 5 $(4.06 \%)$ cases. Successful cases were $90.1 \%$. These results were shown and compared with published literature (Table 3). 
Table 2: Frequency of Complications and successful cases $(n=123$.

\begin{tabular}{lcc}
\hline Post-op Complication & Frequency & Percent \\
\hline Under Correction & 4 & 3.25 \\
Over Correction & 5 & 4.06 \\
abnormal Crease & 2 & 1.62 \\
Upper lid Entropion & 1 & 0.81 \\
Successful cases & 111 & 90.1 \\
Total & 123 & 100 \\
\hline
\end{tabular}

a

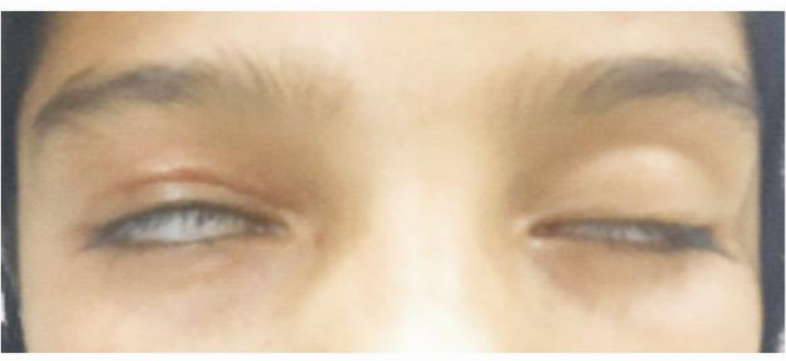

$\mathrm{b}$

Table 3: Comparison of our results with previous studies.

\begin{tabular}{|c|c|c|c|c|}
\hline $\begin{array}{l}\text { S. } \\
\text { No. }\end{array}$ & Author & Followup & $\begin{array}{l}\text { No. of } \\
\text { Cases }\end{array}$ & $\begin{array}{l}\text { Success } \\
\text { Rate } \\
\end{array}$ \\
\hline 1 & Cruz, et al ${ }^{11}$ & 5-85 Months & 35 & 91.4 \\
\hline 2 & Mauriello, et al ${ }^{12}$ & 18 Months & 32 & 87.5 \\
\hline 3 & Press and Hübner ${ }^{13}$ & NA & 44 & 81.8 \\
\hline 4 & $\begin{array}{l}\text { Al-Mujaini and } \\
\text { Wali }^{14}\end{array}$ & $2-24$ Months & 7 & 100 \\
\hline 5 & Decock, et al ${ }^{15}$ & $>1$ Year & 11 & 63.6 \\
\hline 6 & Mete, et $a l^{16}$ & $10-36$ Months & 29 & 69.6 \\
\hline 7 & Lee, et $a l^{17}$ & 40.9 Months & 210 & 93.0 \\
\hline 8 & Present study & 6 Months -5 Years & 123 & 90.1 \\
\hline
\end{tabular}

$\mathrm{NA}=$ Not Available

Figure 1: Common Postoperative Complications: a) Lagophthalmos in the Early Postoperative Period, b) Over Correction at One Month Followup.

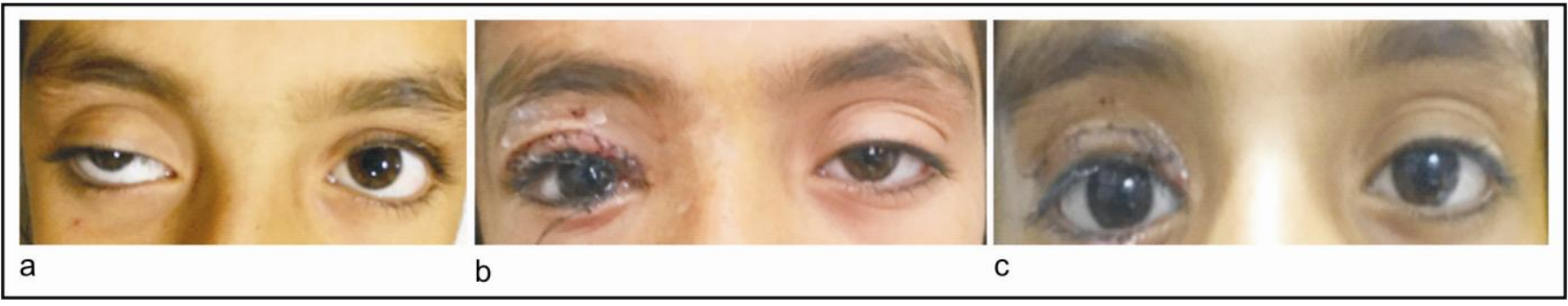

Figure 2. a) Right severe congenital ptosis, b) First Postoperative day, c) At one month after surgery.

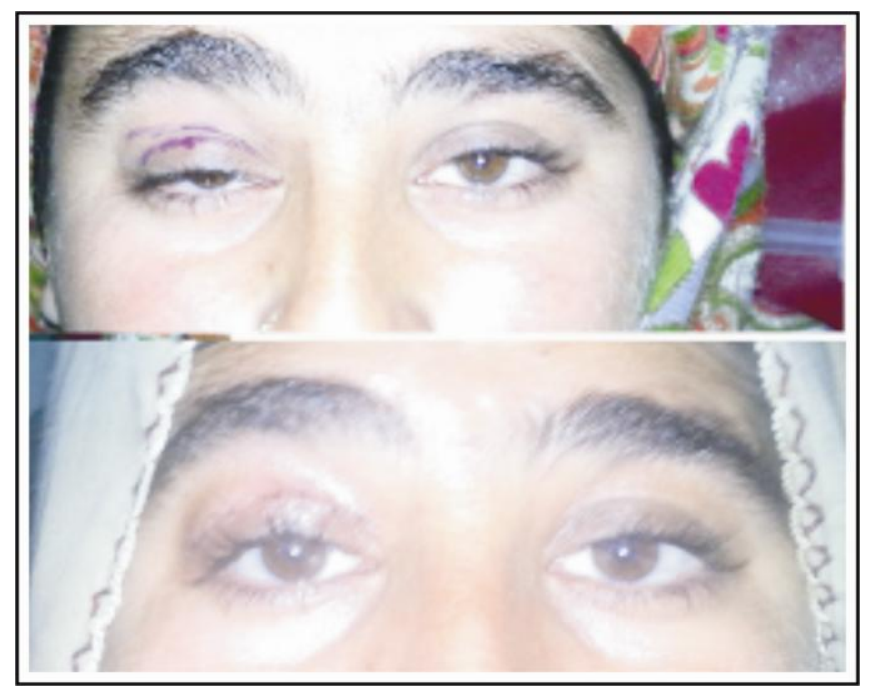

Figure 3: Severe congenital ptosis before and after surgery.

\section{DISCUSSION}

In a study by Bernardini et al, ${ }^{9}$ amount of levator resection was based on the severity and levator muscle function. The aim was to keep eyelid margin 1 to 2 $\mathrm{mm}$ below the super limbus with the patient under general anesthesia and concluded that supra-maximal levator resection has become the procedure of choice for unilateral, poor levator function congenital ptosis."

This audit was used to assess outcome of this procedure which is beneficial for both surgeon and patient as surgical repair of upper lid ptosis correction is a challenging oculoplastic procedure. We compared our results with similar cases in published literature. According to these studies, MLR for severe ptosis was found favorable option with good cosmetic and functional outcome. 
Cruz et $a l^{11}$ studied 35 cases of severe ptosis after MLR with a success rate of $91.4 \%$. Similarly, Mauriello et al, ${ }^{12}$ Press and Hübner, ${ }^{13}$ Al-Mujaini and $\mathrm{Wali}^{14}$, Decock et $a l^{15}$ and Mete et $a l,{ }^{16}$ have results of successful outcome ranging from 63.6 to $100 \%$. The largest cases operated were by Lee et al, ${ }^{17}$ who operated on 210 cases with a success of $93 \%$ at followup of 40.9 months. In the present audit, which included 123 eyelids operated by MLR, success rate was $90.1 \%$ after 6 month to 5 years followup. These results are comparable to the above mentioned studies.

Both FS and MLR have postoperative complications. In a study by Gazzola $\mathrm{R}$ et al, ${ }^{18}$ MLR had fewer complications as compared to FS. Similar finding in favor of MLR was mentioned by Young SM et al. ${ }^{19}$

According to Lee et al, ${ }^{6}$ common postoperative complications were exposure keratopathy, lid crease asymmetry, entropion, overcorrection, eyelash ptosis, temporal eyelid droop, suture abscess and conjunctival prolapse. With proper followup, most of such complications can be managed. In our present audit, 12 cases had different complications. Most common was, overcorrection and under correction. These cases were later managed with conservative treatment and secondary surgery performed to get satisfactory outcome.

Finally long-term followup is important in these cases as postoperative lagophthalmos is common, and needs to be treated at proper time. ${ }^{20}$ Lagophthalmos and exposure keratopathy are common problems after surgery. Commonly known risk factors for lagophthalmos after levator surgery are the severity of the ptosis, LF, and degree of levator complex resection. $^{21,22}$

Young SM et al, concluded that MLR was an effective alternative to FS in congenital ptosis with poor LF. ${ }^{19}$ The risk of postoperative lagophthalmos was related to postoperative lid height rather than preoperative LF. No case of lagophthalmos developed significant exposure keratopathy in the present analysis. Cases with Mild lagophthalmos in initial postoperative period were advised lubricants and massage to reduce over correction.

\section{CONCLUSION}

Maximum levator resection for congenital severe ptosis is a safe and cosmetically acceptable procedure. Followup is important to address postoperative complications at an early time to improve success rate of surgery.

\section{Ethical Approval}

The study was approved by the Institutional review board/Ethical review board (Ref: No.14).

\section{Conflict of Interest}

Authors declared no conflict of interest.

\section{REFERENCES}

1. Koka K, Patel BC. Ptosis Correction. In: StatPearls. Treasure Island (FL): StatPearls Publishing; 2021 Jan-. PMID: 30969650.

2. Yadegari S. Approach to a patient with blepharoptosis. Neurol Sci. 2016; 37 (10): 1589-1596.

Doi: 10.1007/s10072-016-2633-7.

3. Marenco M, Macchi I, Macchi I, Galassi E, Massaro-Giordano M, Lambiase A. Clinical presentation and management of congenital ptosis. Clin Ophthalmol. 2017; 11: 453-463.

Doi: 10.2147/OPTH.S111118.

4. Zikić Z, Ljutica M, Karabeg R, Stamenkovic M. Outcomes of Early Correction of Congenital Myogenic Ptosis Using Transconjunctival Levator Plication. Med Arch. 2020; 74 (3): 205-209.

Doi: 10.5455/medarh.2020.74.205-209.

5. Lee JH, Kim YD. Surgical treatment of unilateral severe simple congenital ptosis. Taiwan J Ophthalmol. 2018; 8 (1): 3-8. Doi: 10.4103/tjo.tjo_70_17.

6. Lee JH, Aryasit O, Kim YD, Woo KI, Lee L, Johnson ON 3rd. Maximal levator resection in unilateral congenital ptosis with poor levator function. Br J Ophthalmol. 2017; 101 (6): 740-746.

Doi: 10.1136/bjophthalmol-2016-309163.

7. Jubbal KT, Kania K, Braun TL, Katowitz WR, Marx DP. Pediatric blepharoptosis. Semin Plast Surg. 2017; 31: 58-64.

8. Shah KP, Mukherjee B. Efficacy of frontalis suspension with silicone rods in ptosis patients with poor Bell's phenomenon. Taiwan J Ophthalmol. 2017; 7 (3): 143-148. Doi: 10.4103/tjo.tjo_36_17.

9. Bernardini FP. Supramaximal Levator Resection for Poor Function Congenital Ptosis, Ophthal Plast Reconstr Surg. 2019; 35 (5): e126. Doi: 10.1097/IOP.0000000000001341

10. Rakha TM, El Saadani AEKI, Awara AM, Mandour SS. Evaluation of intraoperative lagophthalmos formula for levator resection in congenital ptosis in Egyptian patients. Eur J Ophthalmol. 2020 Aug. 17: 1120672120951760. Doi: $10.1177 / 1120672120951760$. 
11. Cruz AA, Akaishi PM, Mendonça AK, Bernadini F, Devoto M, Garcia DM, et al. Supramaximal levator resection for unilateral congenital ptosis: Cosmetic and functional results. Ophthal Plast Reconstr Surg. 2014; 30: 366-371.

12. Mauriello JA, Wagner RS, Caputo AR, Natale B, Lister M. Treatment of congenital ptosis by maximal levator resection. Ophthalmology, 1986; 93: 466-469.

13. Press UP, Hübner H. Maximal levator resection in the treatment of unilateral congenital ptosis with poor levator function. Orbit, 2001; 20: 125-129.

14. Al-Mujaini A, Wali UK. Total levator aponeurosis resection for primary congenital ptosis with very poor levator function. Oman J Ophthalmol. 2010; 3: 122-125.

15. Decock CE, Shah AD, Delaey C, Forsyth R, Bauters W, Kestelyn P, et al. Increased levator muscle function by supramaximal resection in patients with blepharophimosis-ptosis-epicanthus inversus syndrome. Arch Ophthalmol. 2011; 129: 1018-1022.

16. Mete A, Cagatay HH, Pamukcu C, Kimyon S, Saygılı O, Güngör K, et al. Maximal levator muscle resection for primary congenital blepharoptosis with poor levator function. Semin Ophthalmol. 2017; 32: 270-275.

17. Lee JH, Aryasit O, Kim YD, Woo KI, Lee L, Johnson ON 3rd, et al. Maximal levator resection in unilateral congenital ptosis with poor levator function. Br J Ophthalmol. 2017; 101: 740-746.

18. Gazzola R, Piozzi E, Vaienti L, Wilhelm Baruffaldi Preis F. Therapeutic Algorithm for Congenital Ptosis Repair with Levator Resection and Frontalis Suspension: Results and Literature Review. Semin Ophthalmol. 2018; 33 (4): 454-460.

Doi: 10.1080/08820538.2017.1297840.
19. Young SM, Imagawa Y, Kim YD, Park JW, Jang J, Woo KI. Lagophthalmos after congenital ptosis surgery: comparison between maximal levator resection and frontalis sling operation. Eye (Lond). 2021; 35 (4): 1261-1267. Doi: 10.1038/s41433-020-1081-z.

20. Mokhtarzadeh A, Bradley EA. Safety and Long-term Outcomes of Congenital Ptosis Surgery: A PopulationBased Study. J Pediatr Ophthalmol Strabismus, 2016; 53 (4): 212-217. Doi: 10.3928/01913913-20160511-02.

21. Berry-Brincat A, Willshaw H. Paediatric blepharoptosis: a 10-year review. Eye, 2009; 23: 15541559.

22. Iljin A, Loba A, Omulecki W, Zielin rski A. Congenital blepharoptosis: part I. Evaluation of the results of surgical treatment for congenital blepharoptosis. Acta Chir Plast. 2003; 45: 8-12.

\section{Authors' Designation and Contribution}

Mohammad Idris; Assistant Professor: Concepts, Design, Literature Search, Data Acquisition, Data Analysis, Manuscript Preparation, Manuscript Editing, Manuscript Review.

Hassan Yaqoob; Associate Professor: Concepts, Design, Literature Search, Data Acquisition, Manuscript Preparation, Manuscript Editing.

Hadia Sabir; Trainee: Literature Search, Data Acquisition, Statistical Analysis, Manuscript Preparation, Manuscript Editing.

Hera Fahim; Trainee: Literature Search, Data Acquisition.

Muhammad Jamshed; Trainee: Data Analysis, Manuscript Review. 